\title{
ANALISIS STRATEGI FINANCIAL TECHNOLOGY PEER-TO-PEER LENDING PT CROWDE MEMBANGUN BANGSA SEBAGAI PERMODALAN PERTANIAN DIGITAL
}

\section{Ignatia Rahmadani Putri Palupi*, Agriani Hermita Sadeli, Tuti Karyani, Endah Djuwendah}

Program Studi Agribisnis, Fakultas Pertanian, Universitas Padjadjaran

Jl. Raya Bandung - Sumedang Km 21, Hegarmanah, Jatinangor, Sumedang 45363

*Corresponding author: ignatiaupik@gmail.com

\begin{abstract}
Capital is one of the most important factors in conducting a business. These days, farmers are still struggling to access loans as their capital from financial institutions due to complex requirements to fulfill and wholesalers that are not profitable for farmers. The solution to this problem is the utilization of financial technology with a Peer-to-Peer Lending system. PT CROWDE Membangun Bangsa is one of the start-ups that conducted a Peer-to-Peer Lending system in Indonesia. This study aimed to identify the strategy that the company uses to distribute digital capital to farmers by using SOAR analysis. SOAR analysis focuses on the strength and results the company wants to achieve and creates a strategy to increase farmers' productivity and company profits. The results of this study were strategies the company can apply to increase farmer's productivity by creating a program with farmers to adjust the agriculture practices theoretically and practically, empower farmers to do the post-harvest process, and increase partnership with other institutions to supply agriculture inputs and human resources such as agronomist.
\end{abstract}

Keywords: capital, financial technology, peer-to-peer lending, SOAR Analysis

\begin{abstract}
Abstrak: Permodalan merupakan salah satu faktor penting dalam menjalankan sebuah usaha. Saat ini petani masih kesulitan untuk mengakses permodalan yang mudah dari institusi keuangan karena persyaratannya yang sulit untuk dipenuhi. Selain itu, terdapat tengkulak yang tidak memberikan keuntungan cukup untuk petani dari pembelian hasil panennya. Solusi dalam mengatasi masalah tersebut yaitu dengan menggunakan financial technology dengan sistem Peer-to-Peer Lending. Penelitian ini bertujuan untuk mengetahui strategi yang dilakukan dalam memberikan permodalan pertanian secara digital, dengan menggunakan analisis SOAR. Analisis SOAR berfokus kepada kekuatan dan hasil yang ingin dicapai perusahaan untuk menciptakan strategi yang dapat membantu dalam meningkatkan produktivitas petani mitra serta keuntungan perusahaan. Hasil penelitian ini yaitu strategi yang dapat diterapkan untuk meningkatkan produktivitas usahatani yaitu dengan mengadakan program bersama petani mitra untuk penyesuaian cara budidaya secara teori dan praktikal, memberdayakan petani dalam pengolahan pasca panen, serta meningkatkan kerjasama dengan institusi dalam memberikan pasokan saprotan dan sumber daya agronomist.
\end{abstract}

Kata kunci: permodalan, financial technology, peer-to-peer lending, analisis SOAR

\section{PENDAHULUAN}

Pertanian merupakan salah satu identitas negara Indonesia sebagai negara agraris karena mayoritas masyarakatnya mengandalkan sektor pertanian sebagai sumber pendapatan utama. Menurut data Badan Pusat Statistik pada tahun 2019, sektor pertanian di Indonesia merupakan 
Palupi, I. R. P., Sadeli, A. H., Karyani, T., Djuwenda, E. : Analisis Strategi Financial ...

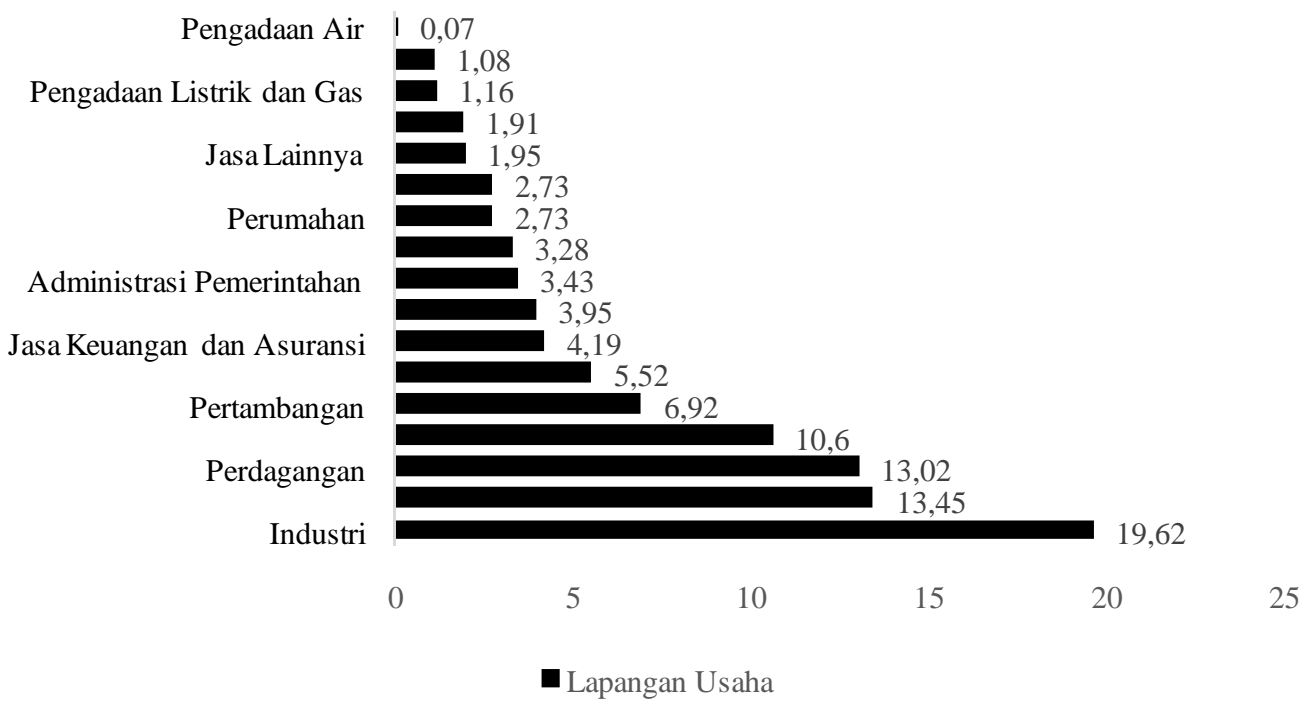

Gambar 1. Kontribusi pertanian dalam PDB di Indonesia tahun 2019 Sumber: Badan Pusat Statistik (2020)

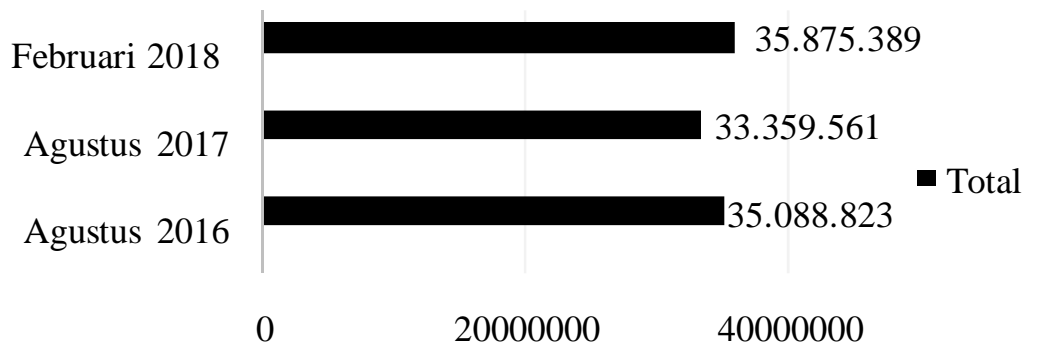

Gambar 2. Jumlah tenaga kerja pertanian menurut provinsi, 2016-2018 Sumber: Sakernas Badan Pusat Statistik, 2018

salah satu sektor utama dalam pembangunan nasional karena merupakan salah satu sektor dengan kontribusi terbesar kedua dalam Produk Domestik Bruto (PDB) menurut lapangan usaha secara persentase.

Posisi pertanian merupakan sektor kedua penyumbang PDB terbesar. Disamping itu sektor pertanian juga menyerap tenaga kerja yang cukup besar di Indonesia. Data menunjukkan bahwa pada bulan Februari 2018 sebanyak 35.875.389 penduduk Indonesia masih bergantung pada sektor pertanian sebagai sumber mata pencahariannya (Sakernas Badan Pusat Statistik, 2018). Terdapat 27,7 juta orang hidup di bawah garis kemiskinan dan 21\% diantaranya berprofesi sebagai petani.

Himpunan Kerukunan Tani Indonesia (HKTI) menyatakan bahwa terdapat lima masalah yang masih menimpa sektor pertanian selama lima tahun kedepan yaitu teknologi, lahan yang semakin sulit, persoalan pupuk, pemasaran dan permodalan. Menurut Van der Meulen dan Van Asseldonk dalam Pratiwi et al., (2020) permodalan dapat digunakan para petani dalam melakukan ekspansi lahan dan investasi dalam menggunakan teknologi.

Modal adalah sekumpulan uang atau barang yang dapat digunakan sebagai dasar untuk melaksanakan suatu pekerjaan. Modal usaha dibutuhkan untuk dapat menjalankan produksi atau budidaya. Modal merupakan salah satu kendala dari sisi keuangan untuk mengembangkan usaha agribisnis. Pembiayaan pada sector pertanian biasanya sulit didapat karena karakteristik usaha agribisnis yang memiliki risiko tinggi (Renaldi et al., 2013). Pada umumnya permodalan di sektor pertanian didapatkan dari lembaga keuangan 
konvensional seperti bank dan koperasi dan lembaga pemerintah (Thaker et al., 2020; Avisha et al., 2019)

Start-Up Financial Technology mempermudah UMKM seperti petani di pedesaan dengan memberikan akses yang lebih mudah dalam permodalan dan meningkatkan efisiensi dengan bunga yang rendah (Anikina et al., 2016). Financial Technology memberikan kemudahan dan kecepatan dari proses transaksi dalam sektor keuangan untuk masyarakat terutama dalam peminjaman dana (Saksonova dan Kuzmina-Merlino, 2017). Peer-to-Peer $(P 2 P)$ Lending menjadi salah satu alternatif untuk investasi dalam bidang permodalan sebagai sumber pendanaan yang praktis untuk masyarakat karena dengan melakukan investasi dengan sistem Peer-to-Peer (P2P) Lending, peminjam dapat mendapatkan return yang cukup menjanjikan (Darman, 2019).

CROWDE merupakan salah satu start up pertanian yang menjadi platform dalam bidang khusus permodalan dengan sistem Peer-to-Peer (P2P) Lending (Stefany dan Sari, 2019). CROWDE bekerja dengan cara menghubungkan kedua pihak dalam industri pertanian yaitu investor atau lenders dengan para petani atau pelaku bisnis pertanian, seperti toko pertanian, pihak asuransi serta sektor industri yang menyerap hasil panen petani. Saat ini sudah terdapat 18.000 petani dengan komoditas pertanian cabai, padi dan jagung yang bermitra dengan CROWDE dengan permodalan yang sudah disalurkan sebesar Rp123,73 Miliar dari 61.780 investor (lenders) yang telah bergabung dengan CROWDE (CROWDE, 2020). Manajemen strategi akan selalu berkembang sesuai dengan arah dan tujuan tujuan dari perusahaan terkait dalam melakukan penyesuaian yang tepat untuk menjamin keberhasilan perusahaan (Harisudin, 2011). Berdasarkan uraian diatas, tujuan penelitian ini ialah merencanakan strategi perusahaan yang tepat yang dapat diterapkan oleh CROWDE untuk meningkatkan produktivitas usahatani petani mitra melalui permodalan pertanian secara digital.

\section{METODE PENELITIAN}

Penelitian dilaksanakan di PT CROWDE Membangun Bangsa dengan pertimbangan bahwa CROWDE merupakan salah satu startup fintech pertama di Indonesia yang fokus pada sector pertanian. Penelitian dilaksanakan pada bulan Agustus - November 2020. Desain dari pengelitian ini yaitu kualitatif. Data yang digunakan dalam penelitian ini yaitu data primer dan data sekunder. Data primer didapatkan dari pengumpulan informasi dengan melakukan wawancara dan observasi. Wawancara yang dilakukan yaitu dengan pendiri dan CEO CROWDE, Team Leader Divisi Operasional, anggota divisi operasional dan salah satu petani mitra CROWDE. Data sekunder didapatkan dari studi literatur dari sumber yang terpercaya seperti jurnal dan situs internet perusahaan. Data yang didapatkan dari lapangan dianalisis untuk mendapatkan informasi secara mendalam dan berupa temuan baru yang bersifat deskriptif (Sugiyono, 2017).

Hasil penelitian dianalisis dengan menggunakan analisis SOAR. Analisis SOAR

\begin{tabular}{|c|c|c|}
$\begin{array}{c}\text { Faktor } \\
\text { Internal } \\
\text { Eksternal }\end{array}$ & $\begin{array}{c}\text { Strength (S): } \\
\text { Daftar kekuatan internal } \\
\text { perusahanan }\end{array}$ & $\begin{array}{c}\text { Opportunitiy (O): } \\
\text { Daftar peluang dari eksternal } \\
\text { perusahaan }\end{array}$ \\
\hline $\begin{array}{c}\text { Aspiration (A) } \\
\text { Daftar aspirasi / harapan dari } \\
\text { internal perusahaan }\end{array}$ & $\begin{array}{c}\text { Strategi SA } \\
\text { Menciptakan strategi yang } \\
\text { menggunakan kekuatan untuk } \\
\text { mencapai aspirasi }\end{array}$ & $\begin{array}{c}\text { Strategi OA } \\
\text { Menciptakan strategi berdasarkan } \\
\text { aspirasi yang diharapkan dan } \\
\text { memanfaatkan peluang yang ada }\end{array}$ \\
\hline $\begin{array}{c}\text { Result (R) } \\
\text { Daftar hasil terukur yang akan } \\
\text { diwujudkan }\end{array}$ & $\begin{array}{c}\text { Strategi SR } \\
\text { Menciptakan strategi yang } \\
\text { menggunakan kekuatan untuk } \\
\text { hasil yang terukur }\end{array}$ & $\begin{array}{c}\text { Strategi OR } \\
\text { Menciptakan strategi dengan } \\
\text { melihat peluang yang ada untuk } \\
\text { mencapai visi perusahaan }\end{array}$ \\
\hline
\end{tabular}

Gambar 3. Matriks SOAR 
merupakan analisis dengan mengidentifikasi faktor eksternal dan internal perusahaan yaitu kekuatan, peluang, aspirasi dan hasil yang diharapkan dan ingin dicapai oleh perusahaan. Perumusan strategi dan hasil strategi yang didapatkan merupakan kombinasi dari perhitungan nilai Strength, Opportunity, Aspiration dan Result dengan menggunakan matriks SOAR (Gambar 3).

\section{HASIL DAN PEMBAHASAN}

\section{Gambaran Umum Perusahaan}

PT CROWDE Membangun Bangsa didirikan pada bulan September tahun 2015 dengan keinginan untuk membantu para petani di Indonesia dalam memberikan akses permodalan dan teknologi. CROWDE memiliki visi untuk merevolusi sector pertanian di Indonesia melalui permodalan dan teknologi. Dalam mencapai visi tersebut, CROWDE melaksanakan misi mereka yaitu dengan memberikan akses permodalan dan pasar kepada para petani dan juga melakukan pendampingan, yang juga berdampak dalam meningkatkan inklusi keuangan bagi para petani di Indonesia dan memberikan akses pasar sehingga dapat meningkatkan kesejahteraan hidup secara ekonomi bagi para petani mitra. Komoditas utama yang diusahakan oleh perusahaan yaitu cabai, jagung dan padi yang tersebar di daerah wilayah Sumatera, Jawa Barat, Jawa Tengah dan Lombok.

\section{Skema Bisnis dan Sistem Peminjaman Modal Perusahaan}

Skema bisnis yang dilakukan di PT CROWDE Membangun Bangsa yaitu dengan memberikan permodalan menggunakan skema pinjaman. Pinjaman modal yang diberikan kepada petani yaitu dalam bentuk barang yang merupakan pasokan sarana dan produksi pertanian seperti benih, pupuk, obat pestisida dan tenaga kerja petani. Penyaluran modal tersebut berbeda pada masing-masing komoditas cabai, padi dan jagung dalam frekuensi penyaluran dananya sesuai dengan kondisi aktual tanaman di lapangan. Dalam sistem peminjaman modal yang diberikan CROWDE terdapat dua bentuk skema pengembalian yang dapat dilakukan oleh petani yaitu skema pengembalian persentase dan pengembalian tonase.

\section{Skema Pengembalian Persentase}

Skema ini merupakan skema pengembalian pinjaman modal dalam bentuk uang yang ditambahkan dengan bunga pinjaman. Rate yang diterapkan pada pinjaman adalah 0,5\% dan 1,5\% per bulan. Ketika petani sudah selesai kegiatan panen dan menjual hasil panennya, maka petani harus membayar pengembalian pinjaman yang diajukan dan ditambah dengan rate per bulan.

\section{Skema Pengembalian Tonase}

Skema ini merupakan skema pengembalian pinjaman modal yang dilakukan CROWDE karena melihat permasalahan yang dihadapi oleh petani dalam akses pasar untuk menjual hasil panennya. Dalam skema ini petani akan menyerahkan hasil panennya dengan jumlah yang sesuai dengan perhitungan dari jumlah pinjaman modal yang diajukan.

\section{Hasil Analisis Faktor Internal}

\section{a. Manajemen}

Kegiatan manajemen yang dilakukan oleh CROWDE dari sisi agribisnis mencakup kegiatan dari hulu sampai hilir. Dimulai dari subsistem pengadaan produksi sebagai modal awal dalam proyek budidaya yang dilakukan oleh petani seperti benih, pupuk, pestisida serta

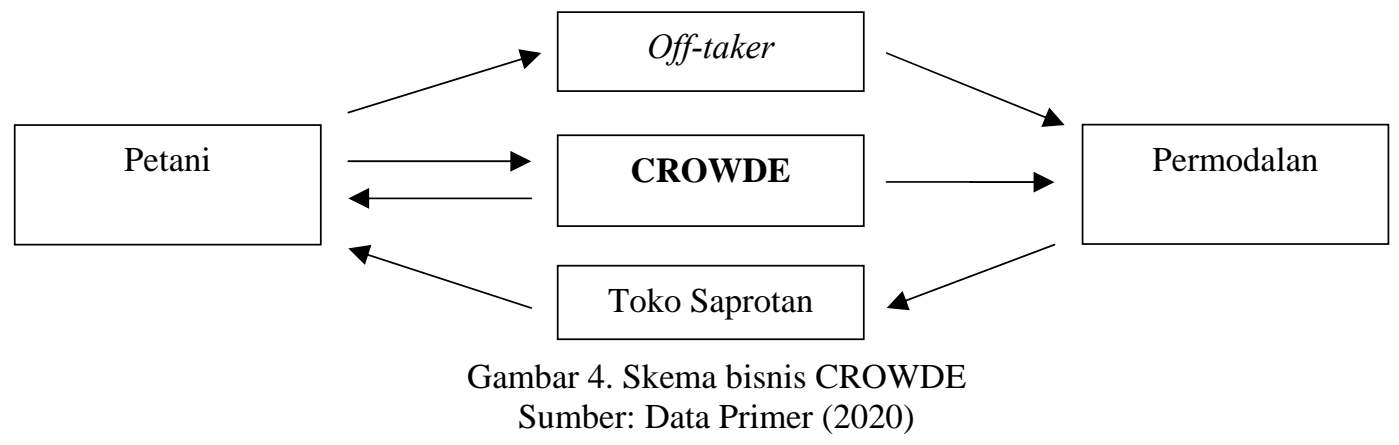


HOK sampai dengan kegiatan panen. Kegiatan yang telah dilakukan petani dipastikan merupakan kegiatan produktif dan hasil panen yang dijual kepada para off-taker dapat memperoleh harga yang sesuai (Gambar 4).

\section{b. Pemasaran}

Pemasaran oleh CROWDE yaitu dengan melakukan pendekatan secara langsung mengenai produk keuangannya kepada para petani melalui Farmers Consultant yang tersebar di berbagai daerah. Selain itu, dalam memasarkan hasil panen dilakukan dengan mendistribusikan kepada perusahaan mitra yang akan membeli hasil panen dengan harga yang sesuai dan dapat memberikan keuntungan kepada para petani.

\section{c. Keuangan}

Salah satu keuntungan yang didapat oleh perusahaan ialah adanya Marketplace Fee. Marketplace Fee merupakan biaya administrasi yang harus dibayarkan oleh petani untuk dapat menjalankan proyek usahatani yang diajukan. Biaya ini harus dibayar oleh petani ketika melakukan pengembalian yang besarnya dipengaruhi oleh beberapa faktor seperti Harga Eceran Tertinggi (HET), Rancangan Anggaran Biaya (RAB), rate pendanaan dan jumlah hasil panen petani.

\section{d. Operasional}

Focus kegiatan operasional perusahaan meliputi proses penyaluran modal yang terintegrasi dengan pendistribusian saprotan kepada petani, pengawasan proyek budidaya sampai kegiatan pemanenan, dan penjualan hasil panen ke off-taker. Adapun kegiatan operasional perusahaan yang memengaruhi performa pada proyek budidaya ialah waktu penyaluran modal dan serangan OPT (Organisme Pengganggu Tanaman). Pada proyek budidaya juga dilakukan monitoring atau pengawasan oleh Field Agent. Pengawasan dilakukan secara terus-menerus sampai selesai kegiatan panen. CROWDE juga memberikan rekomendasi penanganan OPT melalui Field Agent kepada petani mitra.

\section{e. Research and Development}

Salah satu kegiatan penelitian dan pengembangan ialah memberi rekomendasi dalam penanganan serangan OPT pada proyek budidaya yang sedang dikerjakan. Diketahui bahwa serangan OPT dapat memengaruhi produktivitas usahatani dan jumlah pengembalian yang diberikan oleh petani. Ketika rekomendasi yang diberikan kurang efektif, maka akan dilakukan evaluasi untuk perbaikan rekomendasi. Rekomendasi yang efektif dalam menangani serangan OPT akan diperoleh.

\section{f. Manajemen Sistem Informasi}

Sistem informasi yang dilakukan secara langsung kepada para petani melalui Farmers Consultant dan Field Agent di lapangan. Farmers Consultant memberikan informasi kepada para petani di daerah mengenai sistem permodalan digital yang dilakukan oleh CROWDE, sedangkan Field Agent memberi informasi berupa laporan pengawasan dari proyek budidaya yang sedang dikerjakan ke kantor pusat mengenai progress serta kendala dari proyek tersebut.

\section{Hasil Analisis Faktor Internal}

\section{Key External Factors}

\section{a. Ekonomi}

Faktor ekonomi yang dapat memengaruhi yaitu NPL (Non-Performing Loan) yang menunjukkan adanya kredit bermasalah. NPL dipengaruhi oleh proyek usahatani yang gagal memenuhi target panen atau penundaan penanaman akibat faktor cuaca dan serangan OPT. Hal ini memengaruhi kapabilitas petani dalam melakukan pengembalian pinjaman.

\section{b. Sosial, Budaya, Demografi dan Lingkungan}

Faktor sosial budaya berbagai daerah di Indonesia memengaruhi karakteristik petani di berbagai daerah. Misalnya seperti petani di wilayah barat dan petani di wilayah timur memiliki cara bertani yang berbeda dan kepercayaan dalam melakukan aktivitas usahatani yang berbeda termasuk dalam mendapatkan akses permodalan. Hal tersebut memengaruhi CROWDE, terutama ketika memberikan rekomendasi pestisida sebagai salah satu bentuk distribusi permodalan kepada petani di daerah yang berbeda 


\section{c. Politik, pemerintah dan hukum}

Kegiatan dan keberlanjutan CROWDE dalam melakukan aktivitas perusahaannya dipengaruhi oleh adanya peraturan dari Otoritas Jasa Keuangan (OJK) yaitu POJK No.77 Tahun 2016 yang mengatur penyelenggaraan layanan jasa pinjam meminjam berbasis teknologi informasi. Secara hukum, CROWDE telah terdaftar di OJK dan Asosiasi Fintech Pendanaan Bersama Indonesia (AFPI).

\section{d. Teknologi}

Dalam mendukung tujuan dan visi perusahaan pada kegiatan operasional, CROWDE menggunakan teknologi berupa email dan aplikasi Whatsapp. Penggunaan teknologi secara bertahap diterapkan kepada para petani mitra maupun tenaga kerja di lapangan untuk memberikan informasi ke tim kantor pusat.

\section{Competitive Analysis}

\section{a. Persaingan Perusahaan dalam Industri}

Menurut CROWDE, banyaknya start up fintech yang bergerak di sektor pertanian menunjukkan bahwa sector industri pertanian telah semakin berkembang. Dampaknya buat petani ialah semakin banyak pilihan untuk akses permodalan. Berdasarkan hal tersebut, CROWDE mengangap banyaknya startup fintech pertanian lainnya bukan sebuah persaingan, tetapi sebagai hal yang positif.

\section{b. Ancaman Pendatang Baru}

Pendatang atau startup baru yang muncul setelah CROWDE tidak menjadi persoalan atau permasalahan yang dianggap sebagai ancaman bagi perusahaan. CROWDE berusaha untuk meposisikan perusahaannya sebagai center dimana perusahaan lain dapat melakukan kerjasama dengan tujuan yang sama yaitu untuk membantu petani di Indonesia.

\section{c. Ancaman Produk Subsitusi}

Salah satu skema pengembalian pinjaman di CROWDE yang menjadi keunikan yaitu bentuk pengembalian pinjaman modal dalam bentuk tonase atau hasil panen. Dengan adanya skema tersebut dapat menjadi nilai keunggulan dalam menggunakan sistem permodalan yang ditawarkan oleh CROWDE dan akan mempermudah para petani dalam melakukan pengembalian pinjaman modal.

\section{d. Kekuatan Tawar Menawar Pemasok}

Kekuatan tawar menawar pemasok di CROWDE dipengaruhi oleh institusi atau perusahaan mitra baik yang memberikan pasokan dana maupun sarana produksi pertanian seperti benih, pupuk dan pestisida. Peran pemasok di CROWDE yaitu sebagai pihak yang berdiri sebagai subsistem pendukung dari kegiatan agribisnis yang ada di perusahaan yaitu proyek budidaya para petani mitra.

\section{e. Kekuatan Tawar Menawar Pembeli}

Kekuatan tawar menawar pembeli di CROWDE dipengaruhi oleh keberadaan offtaker dalam membeli hasil panen petani mitra. CROWDE memastikan bahwa hasil panen petani mitra dapat dibeli dengan harga yang bagus dan sesuai, sehingga para petani petani dapat pemenuhan jumlah pengembalian pinjaman modal.

Tabel 1. Hasil analisis SOAR

\begin{tabular}{|l|l|l|}
\hline Tabel 1. Hasil analisis SOAR & Opportunity (Peluang) \\
& Strength (Kekuatan) & 1. Pendekatan secara bertahap kepada \\
para petani melalui Farmers & 1. CROWDE berada di salah satu \\
Consultant dan Field Agent yang & sektor yang menjadi tiga kebutuhan \\
dasar manusia yaitu sandang, \\
tersebar di wilayah proyek \\
makan dan papan. (O1) \\
2. Skema permodalan yang mudah \\
untuk digunakan oleh para petani \\
karena prosedur yang mudah untuk \\
dipenuhi. (S2)
\end{tabular}


Palupi, I. R. P., Sadeli, A. H., Karyani, T., Djuwenda, E. : Analisis Strategi Financial ...

Lanjutan Tabel 1

\begin{tabular}{|c|c|c|}
\hline & $\begin{array}{l}\text { 3. Proyek usahatani yang dijalankan } \\
\text { secara berkala dilakukan } \\
\text { pengawasan, pengontrolan dan } \\
\text { evaluasi yang kemudian dapat } \\
\text { dilaporkan secara berkala juga } \\
\text { kepada para lender atau pemberi } \\
\text { pinjaman modal. (S3) } \\
\text { 4. Pendekatan yang dilakukan } \\
\text { langsung kepada para petani di } \\
\text { daerah terpencil atau pedesaan (S4) } \\
\text { 5. Karyawan di CROWDE memiliki } \\
\text { semangat yang sama sesuai } \\
\text { dengan tujuan perusahaan yaitu } \\
\text { untuk membantu para petani di } \\
\text { Indonesia (S5) } \\
\text { 6. Skema pengembalian pinjaman } \\
\text { yang unik yaitu pengembalian } \\
\text { tonase menyesuaikan dengan } \\
\text { kondisi para petani (S6) } \\
\text { 7. Petani dapat memiliki akses lebih } \\
\text { banyak dalam penggunaan } \\
\text { teknologi (S7) } \\
\text { 8. Proyek budidaya yang selalu } \\
\text { diberikan pengawasan dari sisi } \\
\text { agronomi, penyaluran dana dan } \\
\text { operasional (S8) }\end{array}$ & 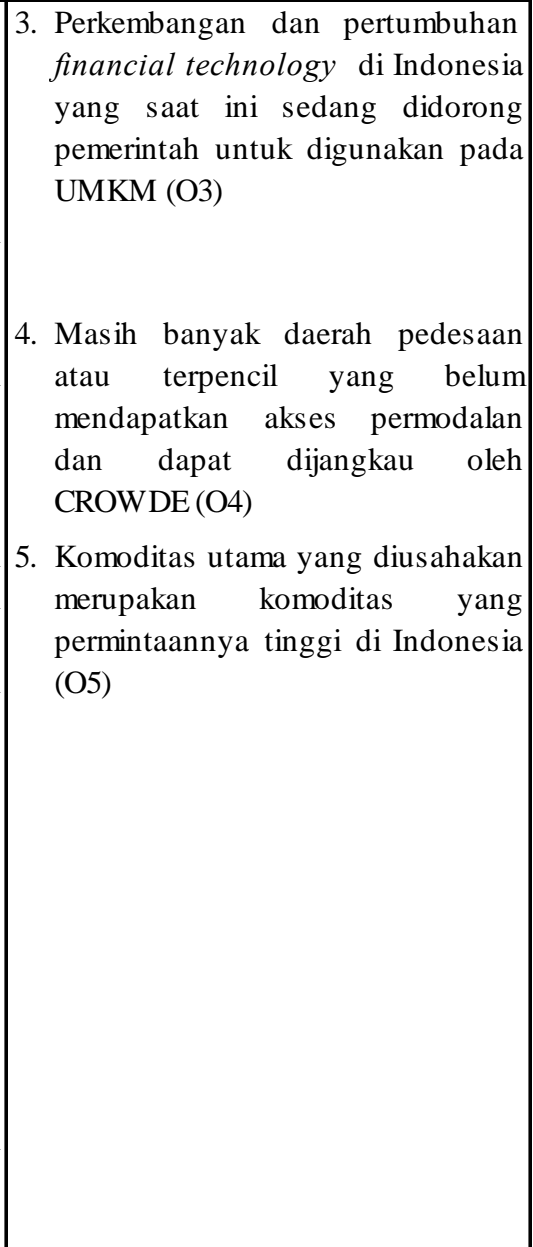 \\
\hline Aspirations (Aspirasi) & Strategi S-A & Strategi O-A \\
\hline 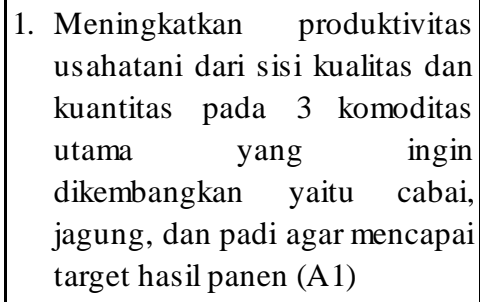 & $\begin{array}{l}\text { 1. Memperluas atau ekspansi daerah } \\
\text { proyek budidaya komoditas utama } \\
\text { secara bertahap (S1, S2, A1, A2) }\end{array}$ & $\begin{array}{l}\text { 1. Memberdayakan para petani untuk } \\
\text { melakukan pengolahan pasca } \\
\text { panen melalui kewirausahaan (O1, } \\
\text { O3, A1, A3) }\end{array}$ \\
\hline $\begin{array}{l}\text { 2. Menjangkau lebih banyak } \\
\text { petani Indonesia } r \text { dan } \\
\text { mempermudah } \\
\begin{array}{l}\text { permodalan untuk } \\
\text { usahatani. (A2) }\end{array}\end{array}$ & $\begin{array}{l}\text { 2. Melakukan akuisisi petani dengan } \\
\text { pendekatan pada kelompok tani } \\
\text { yang berada di daerah pedesaan } \\
\text { tersebut (S1, S4, A2, A3, A4) }\end{array}$ & $\begin{array}{l}\text { 2. Memanfaatkan dukungan dari } \\
\text { pemerintah dengan menggandeng } \\
\text { organisasi atau institusi dibawah } \\
\text { pemerintah untuk perbesar skala } \\
\text { pemberian modal kepada petani } \\
\text { (A2,A3,A4,O2, O3) }\end{array}$ \\
\hline $\begin{array}{l}\text { 3. Mengubah sistem pertanian di } \\
\text { Indoensia dan menjadikan para } \\
\text { petani sebagai subyek atau } \\
\text { peran utama di sektor pertanian } \\
\text { (A3) }\end{array}$ & $\begin{array}{l}\text { 3. Mengadakan program atau acara } \\
\text { bersama dengan petani mitra untuk } \\
\text { penyesuaian cara budidaya secara } \\
\text { teori dan praktikal (S5, S8, A1, A3) }\end{array}$ & $\begin{array}{l}\text { 3. Mengadakan kegiatan atau acara } \\
\text { dengan pemerintah baik kota } \\
\text { maupun daerah kabupaten atau } \\
\text { desa berkaitan dengan start up } \\
\text { financial technology (O3, O4, A3, } \\
\text { A4,A5) }\end{array}$ \\
\hline
\end{tabular}


Palupi, I. R. P., Sadeli, A. H., Karyani, T., Djuwenda, E. : Analisis Strategi Financial ...

Lanjutan Tabel 1

\begin{tabular}{|c|c|c|c|}
\hline \multirow{2}{*}{\multicolumn{2}{|c|}{\begin{tabular}{|l} 
4. Petani di daerah semakin \\
banyak yang dapat mengakses \\
permodalan secara mandiri \\
(A4) \\
5. Meningkatkan literasi keuangan \\
para petani (A5)
\end{tabular}}} & & \\
\hline & & & \\
\hline & esults (Hasil) & Strategi S-R & Strategi O-R \\
\hline & $\begin{array}{l}\text { Peningkatan pada literasi dan } \\
\text { inklusi keuangan para petani } \\
\text { (H1) }\end{array}$ & $\begin{array}{l}\text { 1. Membuat program pelatihan untuk } \\
\text { para petani mitra untuk } \\
\text { meningkatkan literasi keuangan } \\
\text { termasuk perencanaan finansial } \\
\text { petani }(\mathrm{S} 4, \mathrm{H} 1)\end{array}$ & $\begin{array}{l}\text { 1. Mengoptimalkan dukungan dari } \\
\text { pemerintah untuk perbesar skala } \\
\text { operasional bisnis perusahaan di } \\
\text { daerah budidaya petani (O3, H1, } \\
\text { H2, H5) }\end{array}$ \\
\hline 2. & $\begin{array}{l}\text { Peningkatan jumlah petani mitra } \\
\text { di CROWDE (H2) }\end{array}$ & $\begin{array}{l}\text { 2. Membuat program CSR bertema } \\
\text { kewirausahaan untuk mendorong } \\
\text { potensi para petani mitra secara } \\
\text { maksimal (S4, H4) }\end{array}$ & $\begin{array}{l}\text { 2. Menambah saluran pemasaran hasil } \\
\text { panen ke perusahaan manufaktur } \\
\text { makanan dan minuman,e- } \\
\text { commerce, bisnis horeka, UMKM } \\
\text { di daerah budidaya petani (O5,H3, }\end{array}$ \\
\hline 3. & $\begin{array}{l}\text { Peningkatan taraf dan } \\
\text { kesejahteraan hidup para petani } \\
\text { (H3) }\end{array}$ & $\begin{array}{l}\text { 3. Meningkatkan kerjasama dengan } \\
\text { institusi baik swasta maupun } \\
\text { pemerintah dalam memberikan } \\
\text { pasokan sarana produksi pertanian } \\
\text { seperti bahan input pertanian dan } \\
\text { agronomist. (S3, S8, H5, H7) }\end{array}$ & \\
\hline 4. & $\begin{array}{l}\text { Peningkatan pendapatan dan } \\
\text { produktivitas usahatani para } \\
\text { petani mitra (H4) }\end{array}$ & & \\
\hline 5. & $\begin{array}{l}\text { Petani mitra memenuhi target } \\
\text { jumlah panen yang ditentukan } \\
\text { dalam skema pengembalian } \\
\text { pinjaman modal(H5) }\end{array}$ & & \\
\hline 6. & $\begin{array}{l}\text { Petani mendapatkan harga jual } \\
\text { hasil panen yang tinggi (H6) }\end{array}$ & & \\
\hline 7. & $\begin{array}{l}\text { Petani dapat mengembalikan } \\
\text { pinjaman modal sesuai RAB. } \\
\text { (H7) }\end{array}$ & & \\
\hline
\end{tabular}

Sumber: Analisis Data Primer, 2020

Berdasarkan dari hasil analisis matriks SOAR, dirumuskan beberapa strategi yang dapat diprioritaskan untuk dilakukan oleh PT CROWDE Membangun Bangsa untuk dapat meningkatkan produktivitas usahatani yang dapat berpengaruh dalam peningkatan keuntungan perusahaan. Strategi yang dapat membantu dalam mencapai tujuan tersebut yaitu: pemberdayaan petani untuk melakukan pengolahan pasca panen melalui kewirausahaan, mengadakan program atau acara bersama dengan petani mitra untuk penyesuaian cara budidaya secara teori dan praktikal dan meningkatkan kerjasama dengan institusi swasta maupun pemerintah yang bergerak dalam bidang pertanian termasuk universitas untuk memberikan pasokan sarana 
produksi pertanian seperti bahan input pertanian dan agronomist.

Strategi pengolahan pasca panen didukung dengan pernyataan bahwa kewirausahaan dapat meningkatkan kapabilitas seseorang termasuk petani dalam melakukan proses penciptaan nilai tambah pada sebuah produk secara kreatif dan produktif (Dumasari, 2014). Sesuai dengan pernyataan tersebut menunjukkan bahwa kewirausahaan dapat menjadi sebuah peluang yang dapat digunakan untuk memberdayakan dan meningkatkan produktivitas usahatani dari petani mitra di CROWDE. Strategi untuk melakukan penyesuaian cara budidaya secara teori dan praktikal dapat mendukung dilakukannya penerapan Good Agricultural Practices (GAP). Menurut Sudiarto tahun 2010 (Wulandari et al., 2012), penerapan GAP merupakan sebuah alternatif untuk dapat menghasilkan hasil panen yang berkualitas tinggi, aman dan dapat dilihat kembali proses budidaya yang dilakukan sebelum dijual ke pasaran. Strategi kerjasama dengan universitas untuk memberikan pasokan input pertanian dan sumber daya manusia yaitu agronomist juga dapat mendukung strategi kedua dalam mengupayakan adanya penerapan budidaya secara teori dan praktikal berdasarkan Good Agricultural Practices. Ketiga strategi ini bertujuan agar perusahaan dapat mendorong peningkatan produktivitas usahatani serta kualitas layanan yang diberikan dalam penyaluran saprotan untuk aktivitas usahatani petani.

\section{KESIMPULAN}

PT CROWDE Membangun Bangsa telah melakukan strategi yang baik dengan melakukan pendekatan secara bertahap dalam bermitra dengan petani di daerah terpencil dan menerapkan metode pengembalian pinjaman berupa tonase yang disesuaikan dengan kondisi ekonomi dan pasar. Saran untuk meningkatkan produktivitas usahatani petani mitra, maka perusahaan dapat membuat sebuah program dengan melakukan penyesuaian cara budidaya secara teori dan praktikal, pemberdayaan petani untuk melakukan pengolahan pasca panen dan meningkatkan kerjasama dengan institusi swasta maupun pemerintah yang bergerak dalam bidang pertanian termasuk universitas untuk memberikan pasokan sarana produksi pertanian seperti bahan input pertanian dan agronomist.

\section{DAFTAR PUSTAKA}

Avisha, A., Charina, A., Noor, T. I., \& Mukti, G. W. (2019). Crowdfunding sebagai akses alternatif permodalan berbasis teknologi digital pada kegiatan pertanian (Studi kasus di PT Crowde Membangun Bangsa). Mimbar Agribisnis: Jurnal Pemikiran Masyarakat Ilmiah Berwawasan Agribisnis, 5(1), 1-22.

Anikina, I.D., Gukova, V. A., Golodova, A. A. and Chekalkina, A.A. (2016). Methodological aspects of prioritization of financial tools for stimulation of innovative activities. European Research Studies Journal, 19(2), 100-112.

Badan Pusat Statistik. (2018). Statistik Pertanian Indonesia 2018. Jakarta: BPS.

Badan Pusat Statistik. (2020). Pertumbuhan ekonomi Indonesia triwulan IV-2019. Berita Resmi Statistik, XXIV(5 Februari 2020), 1-12.

CROWDE. (2020). Homepage PT CROWDE Membangun Bangsa. Retrieved from https://www.crowde.co/.

Darman. (2019). Financial Technology (FinTech): Karakteristik dan kualitas pinjaman pada peer to peer lending di Indonesia. Jurnal Manajemen Teknologi, 18(2), 130-137.

Dumasari, D. (2014). Kewirausahaan petani dalam pengelolaan bisnis mikro di pedesaan. Ajie, 3(3), 196-202.

Harisudin, M. (2011). Competitive Profile Matrix sebagai alat analisis strategi pemasaran produk atau jasa. Strategic Management, 7(2), 1-6.

Otoritas Jasa Keuangan. (2016). Financial technology. Retrieved from https:// www.ojk.go.id/id/kanal/iknb/financialtechnology/default.aspx.

Pratiwi, P. Y., Yanuarti, I., \& Prihanto, W. (2020). Faktor-faktor yang memengaruhi petani dalam memilih platform 
Palupi, I. R. P., Sadeli, A. H., Karyani, T., Djuwenda, E. : Analisis Strategi Financial ...

crowdfunding (Studi kasus pada petani hortikultura di Desa Sumberejo, Magelang). Ultima Management : Jurnal Ilmu Manajemen, 12(1), 83-103.

Renaldi, E., Karyani, T., Sadeli, A. H., \& Utami, H. N. (2013). Model pembiayaan pra panen pada rantai pasok agribisnis berdasarkan sistem produksi komoditas cabai merah dengan orientasi pasar terstruktur. Sosiohumaniora, 15(3), 253260.

Saksonova, S., \& Kuzmina-Merlino, I. (2017). Fintech as financial innovation - The possibilities and problems of implementation. European Research Studies Journal, 20(3), 961-973.

Stefany, S., \& Sari, W. P. (2019). Strategi marketing public relations PT Crowde Membangun Bangsa dalam meningkatkan minat investasi. Prologia, 2(2), 510-517.

Sugiyono. (2017). Metode Penelitian Kualitatif. Bandung: Alfabeta.

Thaker, H. M. T., Khaliq, A., Sakaran, K. C., \& Thaker, M. A. M. T. (2020). A discourse on the potential of crowdfunding and Islamic finance in the agricultural sector of East Java, Indonesia. Jurnal Ekonomi \& Keuangan Islam, 6(1), 10-23.

Wulandari, E., Perdana, Ma'mun, D., \& Carsono, N. (2012). Peningkatan kapasitas manajerial kelompok tani melalui pelatihan dan pendampingan pencatatan Good Agricultural Practices (GAP) di Desa Tambakan dan Jalan Cagak Kecamatan Jalan Cagak Kabupaten Subang. Dharmakarya: Jurnal Aplikasi Ipteks Untuk Masyarakat, 1(2), 100-108. 